\title{
PENGARUH MODEL PEMBELAJARAN HYBRID TIPE TRADITIONAL CLASESS-REAL WORKSHOP TERHADAP KEMAMPUAN PEMAHAMAN MATEMATIK DITINJAU DARI SELF-CONFIDENCE SISWA
}

\author{
Yoni Sunaryo ${ }^{1}$, Ida Nuraida ${ }^{2}$, Nur Eva Zakiah ${ }^{3}$ \\ 1,2,3Fakultas Keguruan dan IImu Pendidikan, Universitas Galuh Ciamis \\ Email: sunaryoyoni@gmail.com
}

Dikirim: 31 Januari 2018; Diterima: 26 Februari 2018; Dipublikasikan: 31 Maret 2018

\begin{abstract}
ABSTRAK
Perkembangan ilmu pengetahuan dan teknologi perlu diringi dengan peningkatan kualitas sumber daya manusia (SDM). Hal tersebut dapat dilakukan melalui pendidikan. Pendidikan erat kaitannya dengan proses pembelajaran sehingga salah satu cara agar kualitas SDM meningkat adalah dengan pemilihan model pembelajaran yang melibatkan teknologi selama proses pemebalajarannya. Salah satu model pembelajaran yang menggunakan teknologi saat proses pembelajarannya adalah model pembelajaran Hybrid tipe Traditional Classes-Real Workshop. Software yang digunakan adalah geogebra. Penggunaan software geogebra dapat membantu siswa dalam memahami materi pelajaran. Kemampuan pemahaman adalah hal yang penting untuk dilmiliki oleh siswa. Kemampuan pemahaman termasuk aspek kognitif. Aspek lain yang perlu diperhatikan adalah aspek afektif yang salah satunya adalah self-confidence (rasa percaya diri). Oleh karena itu tujuan dari penelitian ini adalah untuk mengetahui pengaruh model pembelajaran Hybrid tipe Traditional Classes-Real Workshop terhadap kemampuan pemahaman matematik ditinjau dari self-confidence siswa. Populasi pada penelitian ini seluruh siswa kelas VIII SMP N 2 Pamarican Tahun Pelajaran 2017/2018. Teknik pengambilan sampel yang digunakan adalah cluster random sampling yang hasilnya adalah kelas VIII D sebagai kelas eksperimen yaitu kelas yang menerima model pembelajaran Hybrid tipe Traditional Classes-Real Workshop dan kelas VIII F sebagai kelas control yaitu kelas yang menerima pembelajaran konvensional. Instrumen yang digunakan adalah soal tes kemampuan pemahaman matematik dan angket berupa skala self-confidence. Hasil penelitian menunjukkan bahwa terdapat pengaruh model pembelajaran Hybrid tipe Traditional Clasess-Real Workshop terhadap kemampuan pemahaman matematik ditinjau dari self-confidence siswa.
\end{abstract}

Kata Kunci: Model pembelajaran Hybrid tipe Traditional Classes-Real Workshop, Model Pembelajaran Berbasis Masalah, Pembelajaran Konvensional, Kemampuan Pemahaman Matematik, Self-Confidence

Cara sitasi: Sunaryo, Y., Nuraida, I., dan Zakiah, N. E. 2018. Pengaruh Model Pembelajaran Hybrid Tipe Traditional Clasess-Real Workshop terhadap Kemampuan Pemahaman Matematik Ditinjau dari Self-Confidence Siswa. Teorema: Teori dan Riset Matematika Vol 2, No 2 (2018). Hal 93-100 


\section{PENDAHULUAN}

Perkembangan zaman adalah hal yang tak dapat dihindari. Oleh sebab itu manusia harus mampu mengimbangi kemajuan ilmu pengetahuan dan teknologi (IPTEK) yang menandai perkembangan zaman tersebut. Pesatnya perkembangan teknologi sebaiknya disertai dengan peningkatan kualitas sumber daya manusia (SDM). Pendidikan merupakan salah satu unsur penting dalam kehidupan yang dapat menunjang terhadap peningkatan kualitas SDM. Melalui pendidikan, manusia akan memperoleh lebih banyak pengetahuan dan keterampilan.

Pendidikan terdiri dari pendidikan formal dan non-formal. Pada pendidikan formal, matematika merupakan pelajaran wajib yang harus diterima oleh siswa sekolah dasar, siswa sekolah menengah dan mahasiswa di sebuah perguruan tinggi. Hal ini menunjukkan pentingnya matematika dipelajari dan dikuasai oleh manusia dalam rangka peningkatan kualitas dirinya. Penguasaan terhadap pelajaran matematika sebaiknya diiringi dengan kemampuan dalam menggunakan teknologi. Hal ini dapat dilakukan melalui proses pembelajaran. Pembelajaran yang dilaksanakan dapat memanfaatkan teknologi yang tepat agar siswa memiliki kemampuan dalam bidang teknologi.

Kurikulum terbaru yaitu kurikulum 2013 memberikan kesempatan yang luas bagi guru untuk menggunakan model pembelajaran yang bervariatif. Kebebasan dalam menggunakan model pembelajaran tercantum dalam silabus mata pelajaran matematika (2016) "Pembelajaran matematika menggunakan pendekatan saintifik yang dapat diperkuat dengan model-model pembelajaran, antara lain: Model Pembelajaran Kooperatif; Pembelajaran Kontekstual; Model Pembelajaran Penemuan Terbimbing; Project Based Learning; dan Problem Based Learning." Pembelajaran yang dilaksanakan tidak terbatas pada jenisjenis model pembelajaran yang telah disebutkan sebelumnya karena faktanya masih banyak model pembelajaran lain yang dapat digunakan dan memfasilitasi siswa dalam mengikuti perkembangan teknologi.

Terdapat sebuah model pembelajaran yang memanfaatkan teknologi dalam proses pembelajarannya. Model pembelajaran tersebut adalah model pembelajaran Hybrid tipe Traditional Clasess-Real Workshop. Hybrid dalam pembelajaran dapat diartikan sebagai gabungan beberapa metode/model/pendekatan pembelajaran untuk mencapai tujuan pembelajaran yang sama. Ruseffendi (dalam Huda, 2015) menyatakan bahwa Traditional Classes merupakan cara pembelajaran tradisional. Traditional Classes merupakan cara pembelajaran tradisional atau lebih dikenal dengan pembelajaran ekspositori. Huda (2015) mengemukakan bahwa Real Workshop merupakan pembelajaran dengan berbantuan media komputer sebagai sarana pembelajaran. Berdasarkan penjelasan tersebut maka model pembelajaran ini merupakan gabungan antara model pembelajaran tradisional (metode ekspositori) dengan model pembelajaran yang menggunakan media komputer. Model pembelajaran Hybrid tipe Traditional Classes-Real Workshop pada penelitian ini menggunakan software Geogebra.

Pengembangan pembelajaran harus membuat siswa menjadi lebih mudah dalam memahami materi yang diajarkan. Hal ini sejalan dengan pendapat Gagne (Pribadi, 2009) pembelajaran diartikan sebagai "a set of event embedded in purposeful activities that facilitate learning". Model pembelajaran Hybrid tipe Traditional Classes-Real Workshop sesuai dengan pendapat Gagne karena dengan model pembelajaran Hybrid tipe Traditional Classes-Real Workshop maka siswa menjadi lebih mudah dalam memahami materi yang diajarkan.

Pemahaman siswa terhadap materi yang diajarkan menunjukkan sejauh mana kemampuan pemahaman matematik siswa. Kemampuan pemahaman merupakan kemampuan berpikir tingkat rendah akan tetapi sangat penting dimiliki oleh siswa. Sebelum siswa mampu berpikir tingkat tinggi maka siswa harus terlebih dahulu mampu berpikir tingkat rendah. Pentingnya siswa memiliki kemampuan pemahaman disampaikan oleh Sunaryo (2017) yang menyatakan "terdapat tiga aspek kemampuan yang harus dimiliki siswa dalam pembelajaran matematika yaitu kemampuan kognitif, afektif dan psikomotor". Kemampuan pemahaman merupakan aspek yang penting dimiliki

Cara sitasi: Sunaryo, Y., Nuraida, I., dan Zakiah, N. E. 2018. Pengaruh Model Pembelajaran Hybrid Tipe Traditional Clasess-Real Workshop terhadap Kemampuan Pemahaman Matematik Ditinjau dari Self-Confidence Siswa. Teorema: Teori dan Riset Matematika Vol 2, No 2 (2018). Hal 93-100 
satu jenis aspek afektif adalah self-confidence (rasa percaya diri). Menurut NCTM (2004) salah satu oleh siswa karena termasuk pada aspek kognitif. Jika siswa sudah memiliki kemampuan pemahaman yang baik maka akan berpengaruh terhadap aspek lainnya yaitu aspek afektif. Salah satu tujuan pembelajaran matematika yang diharapkan ada dalam diri siswa, yaitu siswa menjadi percaya diri terhadap kemampuan diri sendiri dalam mengerjakan matematika (become confidence in their ability to do mathematics).

Berdasarkan uraian tersebut maka tujuan dari penelitian ini adalah untuk melihat pengaruh model pembelajaran Hybrid tipe Traditional Clasess-Real Workshop terhadap kemampuan pemahaman matematik ditinjau dari self-confidence siswa. Model pembelajaran Hybrid tipe Traditional Clasess-Real Workshop dikatakan berpengaruh terhadap kemampuan pemahaman matematik jika rerata kemampuan pemahaman matematik siswa yang memperoleh model pembelajaran Hybrid tipe Traditional Clasess-Real Workshop lebih baik dari siswa yang memperoleh pembelajaran konvensional.

\section{METODE PENELITIAN}

Metode penelitian yang digunakan adalah metode quasi eksperimental atau eksperimen semu. Desain penelitian adalah posttes only control group design. Menurut Arikunto (2009) skemanya sebagai berikut:
$E: X 0$
$C: 0$

Keterangan:

$\mathrm{E}=$ Kelas eksperimen yaitu kelas yang menggunakan model pembelajaran Hybrid tipe Traditional Clasess-Real Workshop

$C=$ Kelas kontrol yaitu kelas yang menggunakan pembelajaran konvensional (pembelajaran berbasis masalah)

$\mathrm{X}=$ Perlakuan pada kelas eksperimen berupa penggunaan model pembelajaran Hybrid tipe Traditional Clasess-Real Workshop

0 = Postes

Populasi penelitian ini adalah seluruh siswa kelas VIII SMP N 2 Pamarican tahun pelajaran 2017/208. Teknik pengambilan sampel yang digunakan adalah cluster random sampling atau acak kelas. Berdasarkan hasil cluster random sampling diperoleh kelas VIII D sebagai kelas eksperimen dan kelas VIII F sebagai kelas control. Instrumen yang digunakan untuk mendapatkan skor postes adalah soal tes kemampuan pemahaman berupa soal uraian sebanyak 5 butir soal. Sedangkan untuk mendapatkan data self-confidence siswa menggunakan angket berupa skala likert yang terdiri dari 22 pernyataan dengan pilihan jawaban sangat setuju, setuju, tidak setuju dan sangat tidak setuju. Pilihan netral dihilangkan untuk menggiring siswa agar memihak.

Soal tes dan skala self-confidence sebelum digunakan sebagai postes terlebih dahulu diujicobakan agar mendapatkan butir soal dan pernyataan yang layak. Penyusunan soal berpedoman pada indikator kemampuan pemahaman sedangakan penyusunan skala self-confidence berpedoman pada indikator self-confidence. Setelah melalui uji coba instrumen dan diperoleh instrumen yang layak selanjutnya kedua instrumen tersedut diberikan kepada siswa di kelas eksperimen dan kelas kontrol setelah selesai pembelajaran di masing-masing kelas yang dilaksanakan sebanyak empat kali pertemuan. Kelas eksperimen memperoleh model pembelajaran Hybrid tipe Traditional Clasess-Real Workshop sedangkan kelas kontrol menggunakan model pembelajaran berbasis masalah karena kurikulum yang digunakan adalah kurikulum 2013.

\section{HASIL DAN PEMBAHASAN}

Berdasarkan hasil analisis data secara keseluruhan diperoleh keterangan bahwa rerata skor postes kelas eksperimen lebih besar dari rerata skor postes kelas kontrol. Berikut disajikan pada Tabel 1.

Cara sitasi: Sunaryo, Y., Nuraida, I., dan Zakiah, N. E. 2018. Pengaruh Model Pembelajaran Hybrid Tipe Traditional Clasess-Real Workshop terhadap Kemampuan Pemahaman Matematik Ditinjau dari Self-Confidence Siswa. Teorema: Teori dan Riset Matematika Vol 2, No 2 (2018). Hal 93-100 
Tabel 1. Rerata Skor Postes Secara Keseluruhan

\begin{tabular}{ccccc}
\hline Kelas & $\mathrm{N}$ & Rerata & $\max$ & $\min$ \\
\hline Eksperimen & 24 & 10,08 & 15 & 7 \\
Kontrol & 24 & 6,83 & 12 & 4
\end{tabular}

Perbandingan rerata kelas eksperimen dan kelas kontrol juga disajikan dalam bentuk diagram batang pada Gambar 1 .

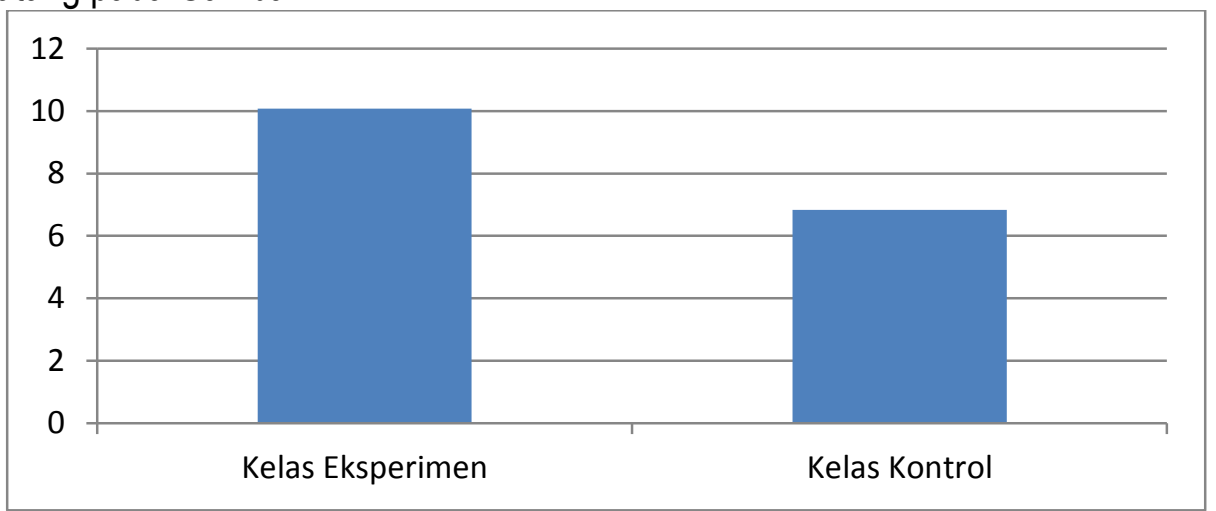

Gambar 1. Perbandingan Rerata Kelas Eksperimen dan Kelas Kontrol

Selain menentukan rerata masing-masing kelas, dilakukan juga pengolahan data skor postes dengan menggunakan statistik inferensial. Hipotesis yang akan diuji adalah :

$$
\begin{aligned}
& \mathrm{H}_{0}: \mu_{x} \leq \mu_{y} \\
& \mathrm{H}_{1}: \mu_{x}>\mu_{y}
\end{aligned}
$$

Keterangan :

$\mu_{x}=$ Parameter rerata postes kelompok eksperimen

$\mu_{y}=$ Parameter rerata postes kelompok kontrol

Hipotesis yang diajukan:

$\mathrm{H}_{0}=$ Kemampuan pemahaman matematik siswa kelas eksperimen tidak lebih baik daripada kelas kontrol.

$\mathrm{H}_{1}=$ Kemampuan pemahaman matematik siswa kelas eksperimen lebih baik daripada kelas kontrol.

Langkah pertama adalah dengan melakukan uji normalitas dengan menggunakan uji Shapiro Wilk. Diperoleh hasil bahwa kelas eksperimen memiliki nilai signifikansi sebesar 0,005 $<0,05$ maka data berdistribusi tidak normal dengakan kelas kontrol memiliki nilai signifikansi sebesar 0,140 $>0,05$ maka data berdistribusi normal. Selanjutnya dilakukan uji Mann Whitney $U$ dan diperoleh hasil signifikansi sebesar $0,012<0,05$ sehingga $\mathrm{H}_{0}$ ditolak dan $\mathrm{H}_{1}$ diterima. Rangkumannya disajikan pada Tabel 2.

Tabel 2. Hasil Analisis Data Postes Secara Keseluruhan

\begin{tabular}{ccc}
\hline & Shapiro Wilk & Mann Whitney $U$ \\
\hline Kelas & sig. & sig. \\
\hline Eksperimen & 0,005 & 0,012 \\
\hline Kontrol & 0,140 & 0,012 \\
\hline
\end{tabular}

$\mathrm{H}_{1}$ diterima artinya kemampuan pemahaman matematik siswa yang memperoleh model pembelajaran Hybrid tipe Traditional Clasess-Real Workshop lebih baik dari siswa yang memperoleh pembelajaran konvensional. Analisis data juga berdasarkan atau ditinjau dari rasa percaya diri siswa atau self-confidence. Setelah angket disebarkan maka angket diolah sehingga diperoleh keterangan

Cara sitasi: Sunaryo, Y., Nuraida, I., dan Zakiah, N. E. 2018. Pengaruh Model Pembelajaran Hybrid Tipe Traditional Clasess-Real Workshop terhadap Kemampuan Pemahaman Matematik Ditinjau dari Self-Confidence Siswa. Teorema: Teori dan Riset Matematika Vol 2, No 2 (2018). Hal 93-100 
siswa mana saja termasuk ke dalam self-confidence positif dan negatif. Penentuan siswa memiliki self-confidence negatif atau positif berdasarkan rerata skor skala self-confidence. Menurut Suherman dan Yaya (1990) cara menentukan sikap siswa yaitu jika rerata skor siswa lebih besar atau sama dengan rerata skor netral maka sikap siswa positif, sebaliknya jika rerata skor siswa kurang dari rerata skor netral maka sikap siswa negatif. Skor netral pada penelitian ini adalah 3. Hasil perhitungan skor postes ditinjau dari self-confidence siswa disajikan pada Tabel 3.

Tabel 3. Hasil Analisis Skor Postes Ditinjau dari Self-Confidence

\begin{tabular}{ccccccccc}
\hline \multirow{2}{*}{ Kelas } & \multicolumn{9}{c}{ Self-Confidence } \\
\cline { 2 - 10 } & $n$ & rerata & $\max$ & $\min$ & $\mathrm{n}$ & rerata & $\max$ & $\min$ \\
\cline { 2 - 10 } Eksperimen & 14 & 11,79 & 15 & 9 & 10 & 8,8 & 10 & 7 \\
Kontrol & 13 & 8 & 12 & 7 & 11 & 5,45 & 8 & 4 \\
\hline
\end{tabular}

Tabel 3 memperlihatkan bahwa rerata skor postes pada self-confidence klasifikasi positif menunjukkan rerata kelas eksperimen lebih besar dari rerata kelas kontrol. Begitupun pada selfconfidence klasifikasi negatif, rerata kelas eksperimen lebih besar dari rerata kelas kontrol. Perbandingan masing-masing rerata kelas eksperimen dan kelas kontrol pada self-confidence klasifikasi positif dan negatif juga disajikan dalam diagram batang pada Gambar 2.

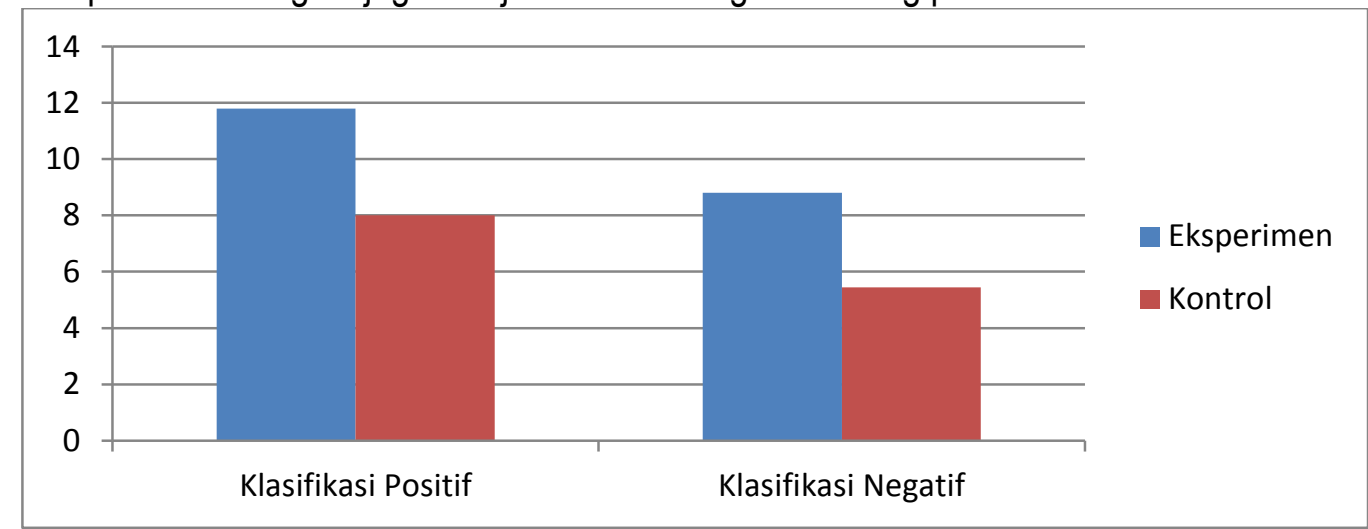

\section{Gambar 2. Perbandingan Rerata Kelas Eksperimen dan Kelas Kontrol Ditinjau dari Self-Confidence Siswa}

Analisis data selanjutnya adalah uji normalitas sebagai prasyarat untuk menentukan pengolahan data selanjutnya apakah menggunakan uji parametrik atau non-parametrik. Hasilnya disajikan pada Tabel 4 .

Tabel 4. Hasil Analisis Data Skor Postes Pada Klasifikasi Posi
\begin{tabular}{|cccc}
\multirow{2}{*}{ Kelas } & \multicolumn{3}{c}{ Uji } \\
\cline { 2 - 4 } & Shapiro Wilk & Levene & $\mathrm{t}$ \\
\cline { 2 - 4 } & sig. & sig. & sig. \\
\hline Eksperimen & 0,14 & \multirow{2}{*}{0,30} & 0,022 \\
\hline Kontrol & 0,61 & & \\
\hline
\end{tabular}

Berdasarkan Tabel 4 terlihat bahwa kelas eksperimen dan kelas kontrol berdistribusi normal karena mamliki nilai signifikansi $0,14>0,05$ dan 0,61>0,05. Maka langkah selanjutnya adalah melakukan uji homogenitas yang hasilnya menunjukkan bahwa data memiliki varians yang homogen karena nilai signifikansi 0,30 >0,05. Dikarenakan data berdistribusi normal dan homogen maka pengujian hipotesis dilakukan dengan uji t. Adapaun hipotesis yang diuji adalah sebagai berikut:

Cara sitasi: Sunaryo, Y., Nuraida, I., dan Zakiah, N. E. 2018. Pengaruh Model Pembelajaran Hybrid Tipe Traditional Clasess-Real Workshop terhadap Kemampuan Pemahaman Matematik Ditinjau dari Self-Confidence Siswa. Teorema: Teori dan Riset Matematika Vol 2, No 2 (2018). Hal 93-100 


$$
\begin{aligned}
& \mathrm{H}_{0}: \mu_{x} \leq \mu_{y} \\
& \mathrm{H}_{1}: \mu_{x}>\mu_{y}
\end{aligned}
$$

Keterangan :

$\mu_{x}=$ Parameter rerata postes kelompok eksperimen

$\mu_{y}=$ Parameter rerata postes kelompok kontrol

Hipotesis yang diajukan:

$\mathrm{H}_{0}=$ Kemampuan pemahaman matematik siswa kelas eksperimen tidak lebih baik daripada kelas kontrol pada self-confidence klasifikasi positif.

$\mathrm{H}_{1}=$ Kemampuan pemahaman matematik siswa kelas eksperimen lebih baik daripada kelas kontrol pada self-confidence klasifikasi positif.

Hasil uji t pada Tabel 4 menunjukkan bahwa signifikansi yang diperoleh sebesar 0,022 < 0,05 maka $\mathrm{H}_{0}$ ditolak dan $\mathrm{H}_{1}$ diterima. Artinya kemampuan pemahaman matematik siswa yang memperoleh model pembelajaran Hybrid tipe Traditional Clasess-Real Workshop lebih baik dari siswa yang memperoleh pembelajaran konvensional pada self-confidence klasifikasi positif.

Pengolahan data juga dilakukan pada siswa yang memiliki self-confidence klasifikasi negatif. Berikut disajikan pada Tabel 5.

Tabel 5. Hasil Analisis Data Skor Postes Pada Klasifikasi Negatif

\begin{tabular}{cccc}
\multirow{2}{*}{ Kelas } & \multicolumn{3}{c}{ Uji } \\
\cline { 2 - 3 } & Shapiro Wilk & Levene & '' \\
\cline { 2 - 3 } & sig. & sig. & sig. \\
\hline Eksperimen & 0,23 & \multirow{2}{*}{0,003} & 0,011 \\
\hline Kontrol & 0,50 & & \\
\hline
\end{tabular}

Berdasarkan Tabel 5 terlihat bahwa kelas eksperimen dan kelas kontrol sama-sama berdistribusi normal karena kelas eksperimen memiliki nilai signifikansi sebesar 0,23>0,05 dan kelas kontrol memiliki nilai signifikansi sebesar $0,50>0,05$. Asumsi kenormalan terpenuhi maka dilanjutkan dengan uji homogenitas varian. Hasil uji homogenitas menunjukkan bahwa kedua kelas memiliki varians yang tidak homogen karena memiliki nilai signifikansi 0,003 <0,05. Tahap selanjutnya adalah melakukan ujit'. Adapaun hipotesis yang diuji adalah sebagai berikut:

$$
\begin{aligned}
& \mathrm{H}_{0}: \mu_{x} \leq \mu_{y} \\
& \mathrm{H}_{1}: \mu_{x}>\mu_{y}
\end{aligned}
$$

Keterangan :

$\mu_{x}=$ Parameter rerata postes kelompok eksperimen

$\mu_{y}=$ Parameter rerata postes kelompok kontrol

Hipotesis yang diajukan:

$\mathrm{H}_{0}=$ Kemampuan pemahaman matematik siswa kelas eksperimen tidak lebih baik daripada kelas kontrol pada self-confidence klasifikasi negatif.

$\mathrm{H}_{1}=$ Kemampuan pemahaman matematik siswa kelas eksperimen lebih baik daripada kelas kontrol pada self-confidence klasifikasi negatif.

Berdasarkan hasil perhitungan yang disajikan di Tabel 5 diperoleh hasil bahwa nilai signifikansi yang diperoleh sebesar $0,011<0,05$ sehingga $\mathrm{H}_{0}$ ditolak dan $\mathrm{H}_{1}$ diterima. Artinya kemampuan pemahaman matematik siswa yang memperoleh model pembelajaran Hybrid tipe Traditional ClasessReal Workshop lebih baik dari siswa yang memperoleh pembelajaran konvensional pada selfconfidence klasifikasi negatif.

Cara sitasi: Sunaryo, Y., Nuraida, I., dan Zakiah, N. E. 2018. Pengaruh Model Pembelajaran Hybrid Tipe Traditional Clasess-Real Workshop terhadap Kemampuan Pemahaman Matematik Ditinjau dari Self-Confidence Siswa. Teorema: Teori dan Riset Matematika Vol 2, No 2 (2018). Hal 93-100 
Berdasarkan hasil analisis data baik secara keseluruhan, pada self-confidence klasifikasi positif dan negatif menunjukkan bahwa kemampuan pemahaman matematik siswa yang memperoleh model pembelajaran Hybrid tipe Traditional Clasess-Real Workshop lebih baik dari siswa yang memperoleh pembelajaran konvensional. Ini berarti terdapat pengaruh model pembelajaran Hybrid tipe Traditional Clasess-Real Workshop terhadap kemampuan pemahaman matematik ditinjau dari self-confidence siswa. Pengaruh yang terjadi adalah pengaruh positif sehingga dapat dikatakan bahwa melalui model pembelajaran Hybrid siswa dapat lebih sukses mencapai tujuan pembelajaran. Hasil yang telah diperoleh tentunya merupakan pengaruh dari treatment yang telah dilaksanakan baik di kelas eksperimen maupun di kelas kontrol.

Indikator kemampuan pemahaman yang digunakan pada penelitian ini adalah indikator menurut Skemp (Hendriana dan Soemarmo, 2014) yaitu pemahaman instrumental yang bermakna dapat hafal suatu konsep tanpa ada kaitannya dengan yang lainnya dan dapat menerapkan rumus untuk mengerjakan perhitungan sederhana dan algoritmik; pemahaman relasional yang bermakna dapat mengkaitkan suatu konsep dengan konsep lainnya. Kedua indikator tersebut dapat terlatih dengan maksimal melalui penggunaan model pembelajaran Hybrid tipe Traditional Clasess-Real Workshop karena pada langkah pembelajarannya siswa menggunakan software geogebra. Penggunaan software geogebra ini dapat membantu siswa dalam proses memahami materi pelajaran terutama materi persamaan garis lurus karena pada saat menyelesaikan soal latihan yang diberikan oleh guru, siswa menggunakan software tersebut. Hal inilah yang dinilai menjadi keunggulan model pembelajaran Hybrid tipe Traditional Clasess-Real Workshop dibandingkan dengan model konvesianal (model pembelajaran berbasis masalah). Model pembelajaran berbasis masalah tidak menggunakan alat bantu software geogebra, hanya menggunakan lembar kerja siswa (LKS) yang tidak dapat memvisualkan materi persamaan garis yang sedang dipelajari.

\section{KESIMPULAN}

Berdasarkan hasil analisis data maka diperoleh kesimpulan bahwa terdapat pengaruh model pembelajaran Hybrid tipe Traditional Clasess-Real Workshop terhadap kemampuan pemahaman matematik ditinjau dari self-confidence siswa.

\section{REKOMENDASI}

Bagi peneliti selanjutnya dapat mencoba membandingkan model pembelajaran Hybrid tipe Traditional Clasess-Real Workshop dengan pembelajaran konvensional selain model pembelajaran berbasis masalah serta pada materi selain persamaan garis yang dinilai cocok menggunakan software baik itu software geogebra ataupun software yang lainnya.

\section{UCAPAN TERIMA KASIH}

Terima kasih kepada kepala sekolah dan guru mata pelajaran matematika SMP Negeri 2 Pamarican yang telah mengizinkan peneliti melaksanakan penelitian.

\section{DAFTAR PUSTAKA}

Arikunto, S. (2009). Manajemen Penelitian. Jakarta : PT Asdi Mahasatya.

Hendriana, H. dan Soemarmo, U. (2014). Penilaian Pembelajaran Matematika. Bandung: PT Refika Aditama.

Huda, M. (2015). Model-model Pengajaran dan Pembelajaran. Yogyakarta: Pustaka Pelajar.

KEMENDIKBUD. (2016). Silabus Mata Pelajaran Sekolah Menengah Pertama/Madrasah Tsanawiyah (SMP/MTs). Jakarta: KEMENDIKBUD.

Cara sitasi: Sunaryo, Y., Nuraida, I., dan Zakiah, N. E. 2018. Pengaruh Model Pembelajaran Hybrid Tipe Traditional Clasess-Real Workshop terhadap Kemampuan Pemahaman Matematik Ditinjau dari Self-Confidence Siswa. Teorema: Teori dan Riset Matematika Vol 2, No 2 (2018). Hal 93-100 
NCTM. (2004). Curriculum and evaluation standard for school mathematics. Virginia: National Council of Teachers of Mathematics.

Suherman dan Yaya K. (1990). Evaluasi Pendidikan Matematika. Bandung : Wijayakusumah.

Sunaryo, Y. (2017). Pengukuran Self-Efficacy Siswa dalam Pembelajaran Matematika di MTs. N 2 Ciamis. Jurnal Teorema : Teori dan Riset Matematika. Vol 1, No 2. ISSN : 2597-7237. Tersedia online: https://jurnal.unigal.ac.id. [15 Februari 2018] 